\title{
National parks influence habitat use of lowland tapirs in adjacent private lands in the Southern Yungas of Argentina
}

\author{
Luis Osvaldo Rivera, Sebastian Martinuzzi, Natalia Politi \\ Sofia Bardavid, Soledad de Bustos, Silvia Chalukian \\ Leonidas Lizárraga, Volker Radeloff and Anna Pidgeon
}

\begin{abstract}
Protected areas are cornerstones of conservation efforts worldwide. However, protected areas do not act in isolation because they are connected with surrounding, unprotected lands. Few studies have evaluated the effects of protected areas on wildlife populations inhabiting private lands in the surrounding landscapes. The lowland tapir Tapirus terrestris is the largest terrestrial mammal of the Neotropics and is categorized as Vulnerable on the IUCN Red List. It is necessary to understand the influence of landscape characteristics on the tapir's habitat use to enable effective conservation management for this species. Our objectives were to (1) determine the potential distribution of the lowland tapir's habitat in the Southern Yungas of Argentina, and (2) evaluate the role of protected areas and other covariates on tapir habitat use in adjacent private lands. We used records of lowland tapirs to model the species' potential distribution and determined habitat use with occupancy modelling. Based on the covariates found to be significant in our models, we constructed predictive maps of probability of habitat use and assessed the area of potential habitat remaining for the species. Probability of habitat use was higher in the vicinity of two national parks and small households than further away from them. We found that in $85 \%$ of the lowland tapir's potential distribution the probability of habitat use is high $(>0.5)$. These areas are near the three national parks in the study area. The probability of detecting lowland tapirs increased with distance to roads. We conclude that national parks play a key role
\end{abstract}

LuIs Osvaldo RIVERA (Corresponding author, (1) orcid.org/0000-0003-29609779), Natalia Politi (@orcid.org/0000-0002-8283-3262) and Sofia Bardavid Instituto de Ecorregiones Andinas, Consejo Nacional de Investigaciones Científicas y Técnicas, Universidad Nacional de Jujuy, San Salvador de Jujuy, Argentina. E-mail luosvriv@yahoo.com

Sebastian MartinuzZi (10 orcid.org/0000-0003-3433-0561), VolkER RadelofF and Anna Pidgeon (이 orcid.org/0000-0002-0090-3352), Department of Forest and Wildlife Ecology, University of Wisconsin-Madison, Madison, USA

SoledAd de Bustos Biodiversity Program, Secretary of Environment of Salta Province, Salta, Argentina

Silvia Chalukian Grupo Argentino de Tapires, IUCN Tapir Specialist Group, Bariloche, Argentina

Leonidas LizÁrRaga National Park Administration of Argentina, Salta, Argentina

Received 21 May 2019. Accepted 13 June 2019. First published online 15 April 2020. in the persistence of lowland tapir populations on adjacent private lands.

Keywords National park, occupancy, potential habitat, private land, road, Southern Yungas, Tapir Conservation Unit, Tapirus terrestris

Supplementary material for this article is available at doi.org/10.1017/So030605319000796

\section{Introduction}

D rotected areas are set aside to conserve species and 1 their habitats, and they are cornerstones of biodiversity conservation worldwide (Ewers \& Rodrigues, 2008). Biodiversity is typically higher and deforestation lower inside protected areas compared to the surrounding landscape, highlighting the effectiveness of area-based conservation (Joppa \& Pfaff, 2010; Geldman et al., 2013; Gray et al., 2016). However, protected areas do not work in isolation because they are embedded within wider landscapes and are connected with surrounding unprotected lands through fluxes of organisms, energy and nutrients (Hansen \& DeFries, 2007). Protected areas may act as refugia that sustain wildlife populations in the surrounding landscapes, especially for large mammals. Wildlife conservation across landscapes thus requires a clear understanding of the interactions between protected areas and the surrounding unprotected lands (McNeely, 1994; DeFries et al., 2007).

Private lands have long been recognized as essential for large mammal conservation (Simonetti, 1999; Hilty \& Merenlender, 2003; Soares-Filho et al., 2006) because limitations in area and representation of habitats in protected areas can impede long-term conservation of populations and species. However, land use around protected areas is considered a major threat to biodiversity (Joppa et al., 2008; Radeloff et al., 2010). Increasing human populations, agricultural expansion and infrastructure development around protected areas reduce wildlife habitat, limit species movements, affect population source-sink dynamics and expose wildlife to anthropogenic threats such as hunting, poaching, invasive exotic species and diseases. These factors potentially limit the conservation value of protected areas 
(Hansen \& DeFries, 2007). Researchers commonly compare habitats and wildlife populations inside vs outside protected areas to assess the effectiveness of protected areas (DeFries et al., 2005; Blake et al., 2008; Geldmann et al., 2013). However, most studies assessing the interaction between protected areas and surrounding lands have focused on the effects of land use and anthropogenic pressures in the surrounding landscape on wildlife populations within protected areas (Woodroffe \& Ginsberg, 1998; Setsaas et al., 2007; Balme et al., 2010; Harrison, 2011; Häkkilä et al., 2017). High levels of anthropogenic disturbance in areas surrounding protected lands usually have a negative effect on species within protected areas (Metzger et al., 2010; Laurance et al., 2012; Häkkilä et al., 2017).

In contrast, the effects of protected areas on wildlife populations inhabiting adjacent private lands have rarely been analysed, especially not in a spatially explicit manner. Typically, the presence of charismatic mammals such as the jaguar Panthera onca, Baird's tapir Tapirus bairdii, primates and ungulates declines with distance from protected areas, but factors such as land-cover type, distance from human settlements and prey richness also influence habitat use (Licona et al., 2011; Carretero-Pinzón et al., 2017; Schank et al., 2017; Petracca et al., 2018). Nonetheless, habitats outside protected areas can have a high probability of wildlife occupancy, as has been reported for the jaguar in Nicaragua (Zeller et al., 2011). Understanding the distribution patterns of charismatic species in landscapes that contain a mosaic of patches with different ownership is useful for understanding the extent of influence of protected areas and the role of adjacent private lands, and for informing conservation decisions. This is particularly applicable in regions with high levels of biodiversity, and where large mammals can serve as indicators of the status of more cryptic species. Such information is also vital in places such as South America, which support high biodiversity and where land is mostly privately owned but that often lack the spatially explicit species-level information required for effective conservation and management.

The lowland tapir Tapirus terrestris is the largest Neotropical land mammal, occurring in forests from northern South America to northern Argentina (Emmons, 1999; Eisenberg \& Redford, 2000). Lowland tapirs can weigh up to $250 \mathrm{~kg}$, with one young produced at most every 18 months, are herbivorous and, although typically occurring at low densities, can be locally abundant around water sources and salt licks (Padilla \& Dowler, 1994; Naveda et al., 2008). The species has an important role as a disperser of tree seeds, thereby engineering the structure and diversity of forests (Bodmer, 1991; Fragoso, 1997; Chalukian et al., 2009), and is categorized as Vulnerable on the IUCN Red List, with a declining population (Naveda et al., 2008). Lowland tapirs use riparian forests and avoid open areas such as grasslands and crops
(Tobler, 2008; Medici, 2010). They keep away from infrastructure, including roads and oil and gas developments, and are unlikely to persist in areas with human densities $>1 / \mathrm{km}^{2}$ (Naveda et al., 2008; Taber et al., 2008). Wellprotected areas such as national parks are probably strongholds for the species (Novaro et al., 2000; Chalukian et al., 2009). In north-west Argentina the lowland tapir inhabits both dry Chaco and Southern Yungas forests, at 100-2,100 m altitude (Taber et al., 2008; Chalukian et al., 2009). Forest loss and fragmentation, illegal hunting, and competition with livestock are the main factors responsible for population declines of lowland tapirs, and they are also chased and killed by dogs (Naveda et al., 2008; Chalukian et al., 2012). In Argentina, the species' range has declined by $46 \%$ in the 20 th century, remaining populations are small and highly fragmented (Chalukian et al., 2009), and the species is categorized as Endangered nationally (Ojeda et al., 2012). Fifty-one Tapir Conservation Units, areas with important or critical habitat for the conservation of the species, have been identified globally based on expert opinion (Taber et al., 2008).

The mountainous, forested region of north-west Argentina known as the Southern Yungas contains four Tapir Conservation Units and three national parks, but most of the land is privately owned. Here, we sought to determine how much potential habitat remains for the lowland tapir in both the Tapir Conservation Units and in the Southern Yungas of Argentina. We also assessed the influence of small human settlements, roads and rivers, and whether properties were categorized as private reserves, on tapir habitat use in private properties adjacent to national parks. We expected a higher degree of human influence at the landscape scale, expressed as shorter distances from human settlements and roads, to be associated with lower habitat use by lowland tapirs. Conversely, proximity to national parks and to water, and categorization as private reserves, were expected to be associated with higher values of habitat use by lowland tapirs.

\section{Study area}

The Southern Yungas in north-west Argentina is the southernmost Neotropical montane forest (Cabrera, 1976). It occurs along the eastern Andean slopes between the Chaco dry forests to the east and the Puna highlands to the west. The area is considered a biodiversity hotspot with high species richness and endemism (Myers et al., 2000). Human activities in the lowlands have transformed $75 \%$ of the Southern Yungas forest into agriculture (Brown \& Malizia, 2004). We carried out our study in the provinces of Salta and Jujuy, in forests that cannot be transformed to other land use according to the current land-use planning scheme (Martinuzzi et al., 2018) and that contain the four Tapir Conservation Units of the Southern Yungas ecoregion (Fig. 1). The study 
area comprises $43,000 \mathrm{~km}^{2}$ of forests and $6,870 \mathrm{~km}^{2}$ of transformed land (mostly agriculture and urban development). Land tenure in the Southern Yungas is characterized by large private properties, some $>1,000 \mathrm{~km}^{2}$ in size, within which local people occupy small households (so-called puestos), where they grow crops for subsistence and practice extensive cattle ranching (Reboratti, 1998). There are three national parks in the study area (Calilegua, Baritu and El Rey National Parks) that have implemented enforcement against human activities, except research and tourism (Burkart, 2005).

\section{Methods}

\section{Camera-trap data}

Camera traps are effective for detecting tapir presence and have been used extensively throughout the Neotropics (Trolle et al., 2007; Cove et al., 2014; Cruz et al., 2014). We selected 125 camera-trap sites within a matrix of Southern Yungas forests, and surveyed them sequentially in groups of 5-10 sites. Camera-trap sites were located in private properties, within a $3^{\circ}$ latitudinal range, and represented different land management objectives (i.e. protection for wildlife vs human use of forest). We did not set up any camera traps within the national parks. Three of the sampled properties are designated as private reserves, where the only permitted human activities are tourism and scientific research. However, there is no enforcement against hunting, poaching or cattle grazing, all of which commonly occur, so private reserves are less protected than national parks. We set up one camera trap (Bushnell Trophy Cam Aggressor, Bushnell, Overland Park, USA) at each site to record lowland tapir presence. Each camera trap was active continuously for 30 days during May-November 2016 and was attached to a tree c. $30 \mathrm{~cm}$ above the ground. We positioned camera traps to maximize detection of lowland tapirs, by placing them along forest trails used by large mammals. Camera traps were separated by at least $1 \mathrm{~km}$ (there is no information available on home range sizes of lowland tapirs in the Southern Yungas).

Our approach was similar to a hierarchical framework (Pearson et al., 2004), and consisted of fitting a model with bioclimatic variables at a larger scale and with low resolution in Maxent 3.4.o (Phillips et al., 2006), followed by occupancy modelling at a more local scale and with a higher resolution (MacKenzie et al., 2006). Occupancy modelling has recently been proposed as a tool for estimating probability of occupancy, habitat use, or as a surrogate of abundance, using co-variables that can influence those parameters at a more local scale, allowing the inference about conservation potential (MacKenzie et al., 2006).

\section{Species distribution model}

We used Maxent (Phillips et al., 2006) to map the lowland tapir's potential distribution. We obtained occurrence data from camera traps used in this study, and also used occurrence data from previous studies (Taber et al., 2008; Fundación CEBio, 2018). To minimize sample bias caused by double counting of individual tapirs, we used only records that were $\geq 2 \mathrm{~km}$ apart. We used eight $1-\mathrm{km}$ resolution bioclimatic variables as predictors, following the precedent of other distribution models for species in the Southern Yungas: annual precipitation (BIO12), annual mean temperature (BIO1), seasonality of precipitation (BIO15) and temperature $\left(\mathrm{BIO}_{4}\right)$, extreme data for precipitation of wettest quarter $(\mathrm{BIO} 16)$, precipitation of driest quarter (BIO17), maximum temperature of warmest month (BIO5) and minimum temperature of coldest month (BIO6; Pidgeon et al., 2015, Martinuzzi et al., 2018). These variables represented conditions in the area during 19502000 (Hijmans et al., 2005). After testing different buffer sizes, we selected a $100 \mathrm{~km}$ buffer and generated 10,000 pseudo-absences within the selected buffer for model training in Maxent (VanDerWal et al., 2009). When running Maxent, we set all other options to default (Phillips, 2017) and assessed model performance with a 10-fold crossvalidation (Bateman et al., 2012) and the area under the receiver operating curve (AUC). To create a map of the species' potential distribution, we transformed predictions from Maxent into a binary map of suitable vs unsuitable habitat, using the 1oth percentile presence logistic threshold. Because in the Southern Yungas lowland tapirs occur only in forests, we deleted non-forested areas from the species' potential distribution map by intersecting the potential distribution with a land-cover map (Martinuzzi et al., 2018). We did not include topographic variables in our modelling because climate and elevation are often highly correlated (Martinuzzi et al., 2018). Finally, we calculated the total area of potential habitat for the species in the study area and in each Tapir Conservation Unit, and the area of transformed land inside each Unit, by intersecting the potential distribution with the land-cover map.

\section{Occupancy modelling}

We used occupancy modelling (MacKenzie et al., 2006) to estimate the probability of the species occurring at a site $(\psi$, probability of habitat use), and the probability of the species being detected if present ( $p$, detection probability), using records in a detection history matrix. We identified biologically meaningful variables known to influence the detection of the species and included these variables in the occupancy models (Long et al., 2011).

We partitioned the detection history of each 30-day camera-trap period into 5-day blocks for a maximum of 

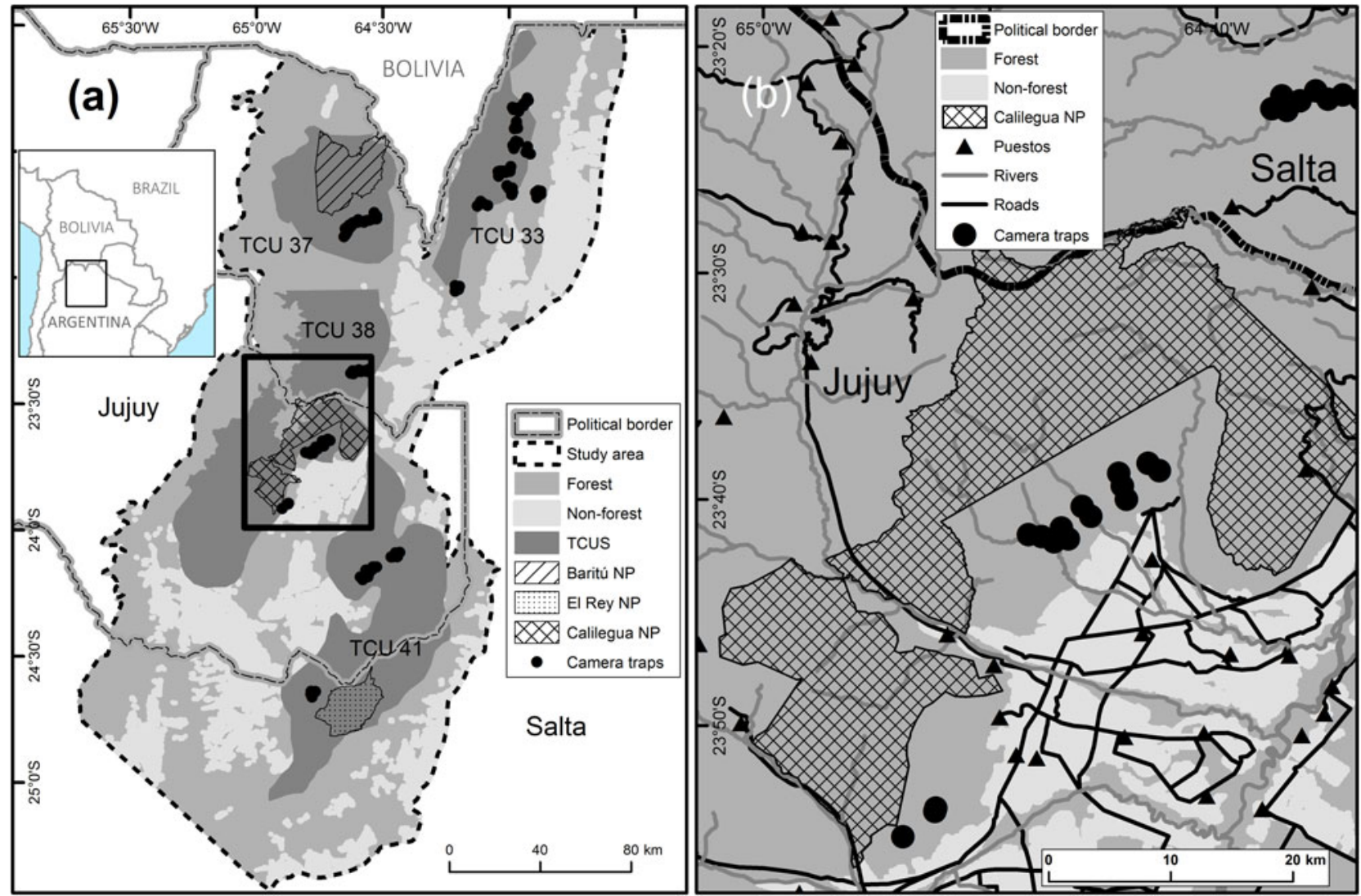

FIG. 1 (a) Study area in the Southern Yungas of Argentina, showing national parks (NP), camera-trap sites, non-forested areas, and Tapir Conservation Units (TCU). (b) Detail of (a) showing camera-trap sites in relation to roads, rivers and puestos.

six repeated lowland tapir surveys of each site. Camera detections of lowland tapirs were defined as independent when they occurred at intervals $>1$ hour (Cove et al., 2014; Cruz et al., 2014).

We selected covariates based on previous studies (Norris, 2014; Ferreguetti et al., 2017) that identified relevant anthropogenic and environmental variables influencing presence and occupancy of lowland tapirs. Variables used were distances to settlements, agricultural lands, roads, water courses and national park boundaries. We did not consider forest cover as a variable, given that all camera traps were placed within forests. We calculated Euclidian distances (in $\mathrm{km}$ ) from camera traps to settlements, agricultural lands, roads, water courses and national park boundaries in ArcGIS 10.3 (Esri, Redlands, USA). We obtained spatial datasets of settlements, roads, water courses and national park boundaries from governmental datasets (IGN, 2016), and of agricultural lands from the available land-cover map (Martinuzzi et al., 2018). Settlements were differentiated into two types: (1) puestos, which are isolated small households inhabited by one or few people, in some instances inhabited only seasonally, and (2) urban centres, defined as settlements with $>2,000$ people (IGN, 2016). To avoid collinearity between covariates we calculated the Pearson correlation coefficient of variable pairs (Supplementary Table 1), and removed one of each pair when correlation was > 0.6 (McDonald et al., 2015; Steenweg et al., 2016). We retained distance from camera traps to nearest roads, puestos, water courses and national park borders. We standardized these variables by converting them to $Z$ scores (to vary between +3 and -3 ; Donovan \& Hines, 2007). Protection of private properties was included as a binary variable ( properties without protection $=0$, private reserves $=1$ ).

We developed 30 a priori models, including a constant (null) and global set (Supplementary Table 2), to estimate the influence of the five variables on the probability of lowland tapir habitat use $(\psi)$. We selected the best models based on the Akaike information criterion (AIC; Burnham \& Anderson, 2002). Rather than choosing the single highest-ranked model, we estimated the mean of the highest-ranked models (i.e. models with $\triangle \mathrm{AIC}<2$ with respect to the top-ranked model; MacKenzie et al., 2006). We determined co-variable effects on $\psi$ and $p$ using the model averaged parameter estimate. If the $95 \%$ confidence intervals for a parameter estimate excluded zero, its effect was considered significant (MacKenzie et al., 2006).

We fitted detection histories and covariates in a singleseason occupancy model implemented in PRESENCE 11.7 
(Hines, 2006). Lowland tapirs are large-bodied mammals capable of travelling long distances between sites (Fragoso, 1997), therefore, $\psi$ was considered to represent habitat use instead of occurrence (MacKenzie et al., 2006). We determined a naïve occupancy estimate for the lowland tapir as the proportion of cameras at which the species was recorded. Finally, we generated a spatially explicit map of estimated habitat use, based on the model averaged variables. For our maps, we established a hexagonal grid of $1 \mathrm{~km}$ diameter cells over the study area. We calculated the value of each variable included in the averaged model for each hexagon using the centroid of each hexagon as the reference point for determining the distances to the nearest national parks, roads and puestos. Given the small size of the hexagons we assumed that conditions at the centroids were representative of conditions in the entire hexagon. We constructed the spatially explicit map of estimated habitat use considering only the area within the potential distribution of the lowland tapir determined with Maxent.

\section{Results}

Of the 125 camera traps set, 116 were active for 30 days, resulting in 3,480 trap nights. This trapping effort yielded 222 photographic records of lowland tapirs, with 146 independent records. Lowland tapirs were recorded at 69 camera traps in 11 of the 12 private properties. The mean nearest distance from camera traps to puestos was $8.7 \pm \mathrm{SE} 0.3 \mathrm{~km}$ (range 3.3-19.6), to roads 7.0 \pm SE $0.3 \mathrm{~km}(1.7-14.5)$, to a national park border $33.4 \pm \mathrm{SE} 2.0 \mathrm{~km}(1.0-65.2)$ and to water courses $1.1 \pm$ SE $0.1 \mathrm{~km}(0.1-6.0)$.

\section{Potential tapir habitat}

We obtained a total of 95 tapir locations for species distribution modelling. The AUC value of the species distribution model was 0.93. Current forest area with potential distribution of the lowland tapir in the study area was $14,452 \mathrm{~km}^{2}$, with $8,301 \mathrm{~km}^{2}$ (57\%) located within Tapir Conservation Units (Supplementary Table 3 ), and $6,151 \mathrm{~km}^{2}$ (43\%) outside these Units. Privately owned properties represent $85 \%$ of the total area of the four Tapir Conservation Units in the Southern Yungas of Argentina (Supplementary Table 3), and $21 \%\left(3,844 \mathrm{~km}^{2}\right)$ of potential habitat have been lost because of forest transformation to other land uses.

\section{Tapir habitat use}

The naive occupancy estimate for the lowland tapir was 0.59. Our single season model assuming constant detection probability at all sites produced a habitat use estimate $\psi=0.65 \pm \mathrm{SE} 0.05(\beta=0.61 \pm \mathrm{SE} 0.23)$ with a detection probability $p=0.32 \pm$ SE $0.03(\beta=-0.73 \pm$ SE 0.12). The value of $\psi$ of Tapir Conservation Unit 33 was almost half of the value of the other Tapir Conservation Units (Supplementary Table 3). The model-averaged estimate for all sites, based on the five models with $\triangle \mathrm{AIC}<2$, was $\psi=0.68 \pm \mathrm{SE} 0.24$ and $p=0.32 \pm \mathrm{SE}$ 0.10. Variables in these well supported models included distances to national parks, roads and puestos, and protection of forests in private reserves. Distance to nearest watercourses was not included in the best models (Table 1). Distance to national park borders and distance to puestos were significantly negatively associated with $\psi$ (Table 2 ). Detection probability $p$ was significantly positively associated with increasing distance to roads (Table 2).

The spatially explicit map of estimated habitat use showed that the majority $(85 \%)$ of the area with potential lowland tapir distribution has a high probability $(>0.5)$ of habitat use (Fig. 2). Areas with the highest probability of habitat use were located near the three national parks (Fig. 2). Conversely, the area of the Southern Yungas with the lowest probability of habitat use was the north-eastern part of the study area, where there are no national parks (Fig. 2).

\section{Discussion}

Habitat use by the lowland tapir on private lands adjacent to national parks was strongly negatively associated with increasing distance to national park borders in the Southern Yungas forests. A clear association between national parks and tapir habitat use is further supported by the low predicted habitat use values in the north-eastern sector of the study area, where there is no strictly protected area. This pattern of association with protected areas corresponds with patterns of lowland tapir habitat use in the Peruvian Amazon (Bodmer, 2000; Bodmer \& Robinson, 2004), and with Baird's tapir persistence in Costa Rica (Cove et al., 2014). We suggest that national parks act as refugia for tapirs, and as sources of tapir dispersal into unprotected areas (Novaro et al., 2000), given that the national parks harbour healthy populations of lowland tapirs in the Southern Yungas (Chalukian et al., 2009). National parks in the Southern Yungas are strictly protected, with surveillance by park rangers and strong law enforcement (Burkart, 2005). The continuous matrix of privately owned forests in which national parks are embedded provides habitat connectivity and facilitates tapir dispersal into the unprotected areas near the national parks. In other regions, where areas immediately adjacent to national parks are exposed to high levels of land transformation and human disturbance, mortality of charismatic species is often high and population declines are common in the surrounding landscape, as a result of edge effects, poaching and conflict with humans (Setsaas et al., 2007; Balme et al., 2010; Häkkilä et al., 2017). For example, in Iguaçu National Park in Brazil, there are strong 
TABLE 1 Top-ranked models for the probability of habitat use $\psi$ and detection probability $p$ of the lowland tapir Tapirus terrestris in the Southern Yungas forest of Argentina, based on Akaike's information criterion (AIC) with a $\Delta$ AIC $<2$ (difference in AIC from the best-ranked model). The table shows the relative model weight (Akaike weight), the likelihood of each model being the best-performing model, the number of model parameters $(k)$ and the -2 log-likelihood output from the occupancy model, implemented in PRESENCE 11.7 (Hines, 2006).

\begin{tabular}{|c|c|c|c|c|c|c|}
\hline Model $^{1}$ & AIC & $\Delta \mathrm{AIC}$ & Akaike weight & Model likelihood & $k$ & -2 log-likelihood \\
\hline$\psi$ (NatParks, Puestos); $p$ (Roads) & 653.66 & 0.00 & 0.35 & 1.00 & 5 & 643.66 \\
\hline$\psi$ (NatParks, Puestos); $p$ (Roads, Puestos, Protection) & 654.86 & 1.20 & 0.19 & 0.55 & 7 & 640.86 \\
\hline$\psi($ NatParks, Puestos); $p$ (Roads, Protection) & 655.07 & 1.41 & 0.17 & 0.49 & 6 & 643.07 \\
\hline$\psi$ (NatParks, Puestos, Roads, Protection); $p$ (Roads) & 655.65 & 1.78 & 0.14 & 0.41 & 7 & 641.44 \\
\hline$\psi$ (NatParks, Puestos, Roads); $p$ (Roads) & 655.94 & 1.99 & 0.13 & 0.37 & 6 & 643.65 \\
\hline
\end{tabular}

${ }^{1}$ Variables: NatParks, distance of camera trap to the nearest national park border; Protection, designation as private reserves; Puestos, distance of camera trap to the nearest puestos (small households); Roads, distance of camera trap to the nearest road.

TABLE 2 Model averaged beta values, standard errors, and 95\% confidence intervals for the variables that affected the probability of habitat use $(\psi)$ and the detection probability $(p)$ of lowland tapirs in the Southern Yungas Forest of Argentina.

\begin{tabular}{|c|c|c|}
\hline Variable & $\begin{array}{l}\text { Parameter } \\
\text { estimates } \pm \mathrm{SE}\end{array}$ & $95 \% \mathrm{CI}$ \\
\hline \multicolumn{3}{|c|}{ Probability of habitat use $(\psi)$} \\
\hline Distance to national park & $-1.23 \pm 0.43^{*}$ & $-2.07--0.39$ \\
\hline Distance to puestos & $-0.63 \pm 0.31^{\star}$ & $-1.24--0.01$ \\
\hline Distance to roads & $-0.01 \pm 0.09$ & $-0.19-0.19$ \\
\hline Private reserve & $-0.24 \pm 0.17$ & $-0.58-0.10$ \\
\hline \multicolumn{3}{|l|}{ Detection probability $(p)$} \\
\hline Distance to roads & $0.41 \pm 0.14^{\star}$ & $0.15-0.68$ \\
\hline Distance to puestos & $0.05 \pm 0.03$ & $-0.01-0.12$ \\
\hline Private reserve & $-0.09 \pm 0.12$ & $-0.33-0.14$ \\
\hline
\end{tabular}

edge effects from adjacent transformed lands inside the protected area, affecting occupancy of several mammals, including lowland tapirs (da Silva et al., 2018). In contrast, in the Southern Yungas the unprotected forests in private lands surrounding national parks appear to have low human disturbance levels, allowing tapirs to persist.

The establishment of Tapir Conservation Units aims to ensure the long-term viability of entire tapir populations, by prioritizing habitats for conservation and identifying and managing threats in those key areas. As we collect more information on the tapir's habitat use and distribution we can refine strategies and improve the delineation of the existing Tapir Conservation Units. In three of the four Tapir Conservation Units in our study area higher habitat use values were partly attributable to the presence of national parks (i.e. Tapir Conservation Unit 37 includes Baritú National Park, Unit 38 includes Calilegua National Park, and Unit 41 includes El Rey National Park). The lower values of habitat use in Unit 33, where there is no national park, further highlight the importance of strict protection of forests for the persistence of lowland tapir populations.

The majority $(57 \%)$ of the potential lowland tapir habitat in the Southern Yungas is included in the Tapir
Conservation Units, but $43 \%$ remains outside. Therefore, we recommend as a priority to evaluate the conservation status of the potential habitat area located outside Tapir Conservation Units. Only $15 \%$ of the forest area in the Tapir Conservation Units is within national parks, whereas $85 \%$ is in private properties. The national parks in the Southern Yungas are probably too small to maintain viable populations of lowland tapirs in the long term. It has been estimated that the home range of lowland tapirs in semideciduous Atlantic Forest is $4.7 \mathrm{~km}^{2}$ and that 200 tapirs would be required to ensure long-term population viability (Medici, 2010). Therefore, in the Southern Yungas the conservation strategy for the lowland tapir should include private forests surrounding national parks in schemes of sustainable management.

We found no evidence that tapir habitat use was higher on protected private reserves than on private lands without protection. This suggests that the protection level afforded by protected private lands, which is lower than that of national parks, is not sufficient to influence habitat use by tapirs. However, these findings must be interpreted cautiously because our sample size was small. Currently, in Argentina the National Forest Law No. 26,331 (Seghezzo et al., 2011) provides a legal framework and financial support for the protection of private land (Rivera et al., 2015), assisting private land owners in supporting the populations of tapirs and other wildlife.

Contrary to our expectations, habitat use by the lowland tapir was higher closer to puestos. One possible explanation is that puestos are in relatively inaccessible locations, with no association with distance to roads, cities, or agricultural lands. Inaccessibility of puestos could offset the effect of some human disturbance such as cattle grazing and smallscale crop farming. It is also possible that tapirs benefit from small-scale forest disturbance caused by local people, as tapirs are known to forage in open and secondary forests (Painter, 1998). Another possible cause of the positive association is that local people living in puestos persecute large predators to reduce cattle predation (Perovic et al., 2015), 


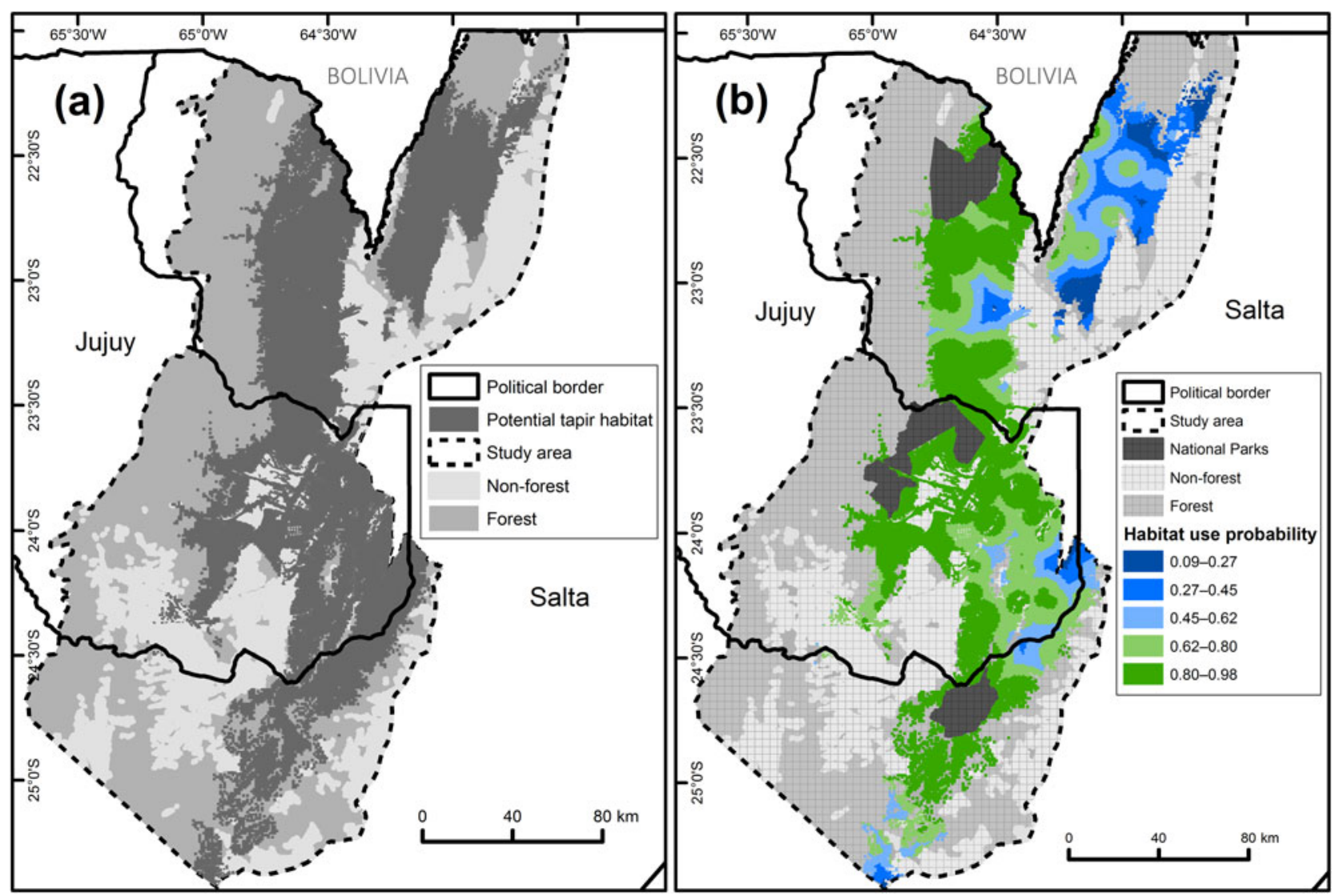

FIG. 2 (a) Potential habitat for the lowland tapir, and (b) spatially explicit map of probability of habitat use for the lowland tapir in the study area.

which may also reduce predation pressure on the lowland tapir. Local people also appear not to rely on hunting tapirs as a protein source. The only evidence of hunting in the study area is from areas with good accessibility by urban hunters (S.C. Chalukian, 2018, pers. comm.), which is why roads affected lowland tapir detectability, as in other regions where roads have provided access for hunters (Licona et al., 2011; Cruz et al., 2014; Schank et al., 2015). Care is thus necessary when planning and building new transport infrastructure in the Southern Yungas, to avoid increasing access to unprotected forested areas (Martinuzzi et al., 2018).

Given the key role of national parks for the conservation of lowland tapir populations in the Southern Yungas, the management effectiveness and implementation of protection actions in these conservation areas must be maintained or improved, with adequate funding and personnel. Tapir Conservation Unit 33 is under increasing anthropogenic pressure, with oil and gas prospecting, extensive cattle ranching, illegal forest logging and wildlife poaching (Salta Government, 2013). We suggest that the lowland tapir and other wildlife species would benefit from the creation of a strictly protected area in Tapir Conservation Unit 33. Otherwise, if the creation of a strictly protected area is not possible, efforts should be made to limit the extent of cattle ranching and strengthen the enforcement of laws against poaching and illegal logging. Given that most of the land within the Tapir Conservation Units is privately owned, collaboration with the private sector is required to protect the lowland tapir and its habitat. This should happen within the framework of the National Forest Law, which aims to support land planning and forest management, including conservation and restoration of ecologically important elements. Connectivity between Tapir Conservation Units is threatened by land-use change, and thus strategies to maintain the remaining structural connectivity are needed urgently, for the benefit of the lowland tapir and other species.

More broadly, our study highlights the importance of protected areas for large mammals, not only by protecting populations inside the protected areas themselves, but also by potentially supporting populations outside, on adjacent private lands. In addition, surrounding areas can increase the total area of available habitat, and hence support larger subpopulations with better chances for long-term survival. However, we caution that studies based on camera traps, such as ours, cannot identify sink habitat, and we were not able to examine demographics and age structure of tapirs inside and outside protected areas. Nevertheless, we suggest that our findings highlight the broader importance of national parks, and the need to carefully examine their value for surrounding areas, especially if those areas are 
not heavily influenced by humans. In the oceans, marine protected areas have been shown to increase fisheries in the surrounding areas in some cases (McClanahan \& Mangi, 2000; Roberts et al., 2001; Lester et al., 2009), and in terrestrial systems, theory and empirical data suggest that spatial controls on hunting, such as those provided by protected or sacred areas, can allow wild populations to persist (McCullough, 1996; Brandt et al., 2013). It may be a missed opportunity that the benefits of protected areas for wildlife populations in unprotected landscapes are not typically considered in conservation planning (Margules \& Pressey, 2000; Naidoo et al., 2006; Keppel et al., 2015).

Acknowledgements We thank the land owners who allowed us to conduct fieldwork on their properties; Francisco Molina and Mariano Odetti for help with fieldwork; Fundación CEBio for logistical support; and the Whitley Fund for Nature for financial support. A Fulbright-CONICET (Consejo Nacional de Investigaciones Científicas y Técnicas) scholarship and CONICET supported the visit of NP and LR to Silvis Lab at University of Wisconsin, Madison.

Author contributions Study concept and design: all authors; data collection: LR, NP, SB, SdB, SCH, LL; data analysis: LR, SM, NP, VR, AP; creation of habitat use maps: LR, SM, NP, VR, AP; writing: LR, SM, NP, VR, AP; revisions: all authors.

\section{Conflict of interest None.}

Ethical standards This research abided by the Oryx guidelines on ethical standards.

\section{References}

Balme, G.A., Slotow, R. \& Hunter, L.T.B. (2010) Edge effects and the impact of non-protected areas in carnivore conservation: leopards in the Phinda-Mkhuze Complex, South Africa. Animal Conservation, 13, 315-323.

Bateman, B.L., VanDerWal, J. \& Johnson, C.N. (2012) Nice weather for bettongs: using weather events, not climate means, in species distribution models. Ecography, 35, 306-314.

Blake, S., Deem, S.L., Strindierg, S., Maisels, F., Momont, L., Isia, I.B. et al. (2008) Roadless wilderness area determines forest elephant movements in the Congo Basin. PLOS ONE, 3, e3546.

BODMER, R.E. (1991) Strategies of seed dispersal and seed predation in Amazonian ungulates. Biotropica, 23, 255-261.

BODMER, R.E. (2000) Integrating hunting and protected areas in the Amazon. In Priorities for the Conservation of Mammalian Diversity (eds A. Entwistle \& N. Dunstone), pp. 277-29o. Cambridge University Press, Cambridge, UK.

Bodmer, R.E. \& Robinson, J.G. (2004) Evaluating the sustainability of wildlife in the Neotropics. In People in Nature: Wildlife Conservation in South and Central America (eds K. Silvius, R.E. Bodmer \& J.M. Fragoso), pp. 299-323. Columbia University Press, New York, USA.

Brandt, J.S., Wood, E.M., Pidgeon, A.M., Han, L.X., Fang, Z. \& Radeloff, V.C. (2013) Sacred forests are keystone structures for forest bird conservation in southwest China's Himalayan Mountains. Biological Conservation, 166, 34-42.

Brown, A.D. \& Malizia, L.R. (2004) The Piedmont forests of the Yungas: in the threshold of extinction. Ciencia Hoy, 83, 52-63.
Burkart, R. (2005) Protected areas of Argentina. In Environmental Status of Argentina 2005 (eds A. Brown, U. Martinez Ortiz, M. Acerbi \& J.F. Corcuera), pp. 399-404. FVSA (Fundación Vida Silvestre Argentina), Buenos Aires, Argentina.

Burnham, K.P. \& Anderson, D.R. (2002) Model Selection and Multimodel Inference: A Practical Information-Theoretic Approach. 2nd edition. Springer Verlag, New York, USA.

Cabrera, A. (1976) Argentine Encyclopedia of Agriculture and Gardening: Phytogeographic Regions of Argentina. Acme, Buenos Aires, Argentina.

Carretero-Pinzon, X., Defler, T.R., McAlpine, C.A., \& Rhodes, J.R. (2017) The influence of landscape relative to site and patch variables on primate distributions in the Colombian Llanos. Landscape Ecology, 32, 883-896.

Chalukian, S., De Bustos, S., Lizárraga, L., Quse, V., Paviolo, A. \& Varela, D. (2009) Action Plan for the Conservation of the Tapir (Tapirus terrestris) in Argentina. Tapir Specialist Group, IUCN, Salta, Argentina.

Chalukian, S., De Bustos, S., Di Bitetti, M., De Angelo, C. \& Paviolo, A. (2012) Order Perissodactyla. In Red Book of the Threatened Mammals of Argentina (eds R.A. Ojeda, V. Chillo \& G.B. Díaz Isenrath), pp. 116. SAREM (Sociedad Argentina para el Estudio de los Mamíferos), Mendoza, Argentina.

Cove, M.V., Pardo Vargas, L.E., de la Cruz, J.C., Spínola, R.M., JaCkson, V.L., SAenz, J.C. \& Chassot, O. (2014) Factors influencing the occurrence of the Endangered Baird's tapir Tapirus bairdii: potential flagship species for a Costa Rican biological corridor. Oryx, 48, 402-409.

Cruz, P., Paviolo, A., Bó, R.F., Thompson, J.J. \& Di Bitetti, M.S. (2014) Daily activity patterns and habitat use of the lowland tapir (Tapirus terrestris) in the Atlantic Forest. Mammalian Biology. 79, 376-383.

da Silva, M.X., Paviolo, A., Tambosi, L.R. \& Pardini, R. (2018) Effectiveness of protected areas for biodiversity conservation: mammal occupancy patterns in the Iguaçu National Park, Brazil. Journal for Nature Conservation, 41, 51-62.

DeFries, R., Hansen, A., Newton, A.C. \& Hansen, M.C. (2005) Increasing isolation of protected areas in tropical forests over the past twenty years. Ecological Applications, 15, 19-26.

DeFries, R., Hansen, A., Turner, B.L., Reid, R. \& Liu, J. (2007) Land use change around protected areas: management to balance human needs and ecological function. Ecological Applications, $17,1031-1038$.

Donovan, T.M. \& Hines, J. (2007) Exercises in Occupancy Modeling and Estimation. The University of Vermont, Burlington, USA. uvm.edu/envnr/vtcfwru/spreadsheets/occupancy.htm [accessed 15 March 2017].

EisenberG, J.F. \& Redford, K.H. (2000) Mammals of the Neotropics (Volume 3): The Central Neotropics: Ecuador, Peru, Bolivia, Brazil. University of Chicago Press, Chicago, USA.

Emmons, L. (1999) Neotropical Rain Forest Mammals: A Field Guide. 2nd edition. University of Chicago Press, Chicago, USA.

Ewers, R.M. \& Rodrigues, A.S. (2008) Estimates of reserve effectiveness are confounded by leakage. Trends in Ecology \& Evolution, 23, 113-116.

Ferreguetti, A.C., Tomas, W.M. \& de Bergallos, H.G. (2017) Density, occupancy, and detectability of lowland tapirs, Tapirus terrestris, in Vale Natural Reserve, south-eastern Brazil. Journal of Mammalogy, 98, 114-123.

FraGoso, J.M.V. (1997) Tapir-generated seed shadows: scale-dependent patchiness in the Amazon rain forest. Journal of Ecology, 85, 519-529.

Fundación CEBio (2018) Fundación CEBio, Jujuy, Argentina. cebio.org.ar [accessed 15 January 2018]. 
Geldmann, J., Barnes, M., Coad, L., Craigie, I.D., Hockings, M. \& BuRGESS, N.D. (2013) Effectiveness of terrestrial protected areas in reducing habitat loss and population declines. Biological Conservation, 161, 230-238.

Gray, C.L., Hill, S.L., Newbold, T., Hudson, L.N., Börger, L., Contu, S. et al. (2016) Local biodiversity is higher inside than outside terrestrial protected areas worldwide. Nature Communications, 7, 12306.

Häkkilä, M., Le Tortorec, E., Brotons, L., Rajasärkkä, A., Tornberg, R. \& Mönkkönen, M. (2017) Degradation in landscape matrix has diverse impacts on diversity in protected areas. PLOS ONE, 12, e0184792.

Hansen, A.J. \& DeFries, R. (2007) Ecological mechanisms linking protected areas to surrounding lands. Ecological Applications, 17, 974-988.

HARRISON, R.D. (2011) Emptying the forest: hunting and the extirpation of wildlife from tropical nature reserves. BioScience, 61, 919-924.

Hijmans, R.J., Cameron, S.E., Parra, J.L., Jones, P.G. \& Jarvis, A. (2005) Very high resolution interpolated climate surfaces for global land areas. International Journal of Climatology, 25, 1965-1978.

Hilty, J. \& Merenlender, A.M. (2003) Studying biodiversity on private lands. Conservation Biology, 17, 132-137.

Hines, J.E. (2006) Program PRESENCE Version 12.7. USGS (United States Geological Survey), Patuxent Wildlife Research Center, Laurel, USA.

IGN (Instituto Geográfico Nacional) (2016) GIS from IGN (National Geographic Institute). ign.gob.ar/sig [accessed 15 February 2017].

Joppa, L.N. \& Pfaff, A. (2010) Global protected area impacts. Proceedings of the Royal Society B, 278, 1633-1638.

Joppa, L.N., Loarie, S.R. \& Pimm, S.L. (2008) On the protection of 'protected areas'. Proceedings of the National Academy of Science of the United States of America, 105, 6673-6678.

Keppel, G., Mokany, K., Wardell-Johnson, G.W., Phillips, B.L., Welbergen, J.A. \& Reside, A.E. (2015) The capacity of refugia for conservation planning under climate change. Frontiers in Ecology and the Environment, 13, 106-112.

Laurance, W.F., Useche, D.C., Rendeiro, J., Kalka, M., Bradshaw, C.J., Sloan, S.P., Arroyo-Rodriguez, V. et al. (2012) Averting biodiversity collapse in tropical forest protected areas. Nature, 489, 290-294.

Lester, S.E., Halpern, B.S., Grorud-Colvert, K., Lubchenco, J., Ruttenberg, B.I., Gaines, S.D. et al. (2009) Biological effects within no-take marine reserves: a global synthesis. Marine Ecology Progress Series, 384, 33-46.

Licona, M., McCleery, R., Collier, B., Brightsmith, D.J. \& LOPEZ, R. (2011) Using ungulate occurrence to evaluate community-based conservation within a biosphere reserve model. Animal Conservation, 14, 206-214.

Long, R.A., Donovan, T.M., MacKa, Y.P., Zielinski, W.J. \& BUZAS, J.S. (2011) Predicting carnivore occurrence with noninvasive surveys and occupancy modeling. Landscape Ecology, 26, 327-340.

Mackenzie, D.I., Nichols, J.D., Royle, J.A., Pollock, K.H., Bailey, L.L. \& Hines, J.E. (2006) Occupancy Estimation and Modeling. Inferring Patterns and Dynamics of Species Occurrence. Academic Press, New York, USA.

Margules, C.R. \& Pressey, R.L. (200o) Systematic conservation planning. Nature, 405, 243-253.

Martinuzzi, S., Rivera, L., Politi, N., Bateman, B.L., De los Llanos, E.R., LizÁrraga, L. et al. (2018) Enhancing biodiversity conservation in existing land-use plans with widely available datasets and spatial analysis techniques. Environmental Conservation, 45, 252-260.
McClanahan, T.R. \& Mangi, S. (2000) Spillover of exploitable fishes from a marine park and its effect on the adjacent fishery. Ecological Applications, 10, 1792-1805.

McCullough, D.R. (1996) Spatially structured populations and harvest theory. The Journal of Wildlife Management, 60, 1-9.

McDonald, P.J., Griffiths, A.D., Nano, C.E., Dickman, C.R., WARD, S.J. \& LUCK, G.W. (2015) Landscape-scale factors determine occupancy of the Critically Endangered central rock-rat in arid Australia: the utility of camera trapping. Biological Conservation, 191, 93-100.

McNeely, J.A. (1994) Protected areas for the 21st century: working to provide benefits to society. Biodiversity and Conservation, 3, 390-405.

Medici, E.P. (2010) Assessing the viability of lowland tapir populations in a fragmented landscape. $\mathrm{PhD}$ thesis. The University of Kent, Canterbury, UK.

Metzger, K.L., Sinclair, A.R.E., Hilborn, R., Hopcraft, J.G.C. \& Mduma, S.A. (2010) Evaluating the protection of wildlife in parks: the case of African buffalo in Serengeti. Biodiversity and Conservation, 19, 3431-3444.

Myers, N., Mittermeier, R.A., Mittermeier, C.G., da Fonseca, G.A.B. \& KenT, J. (2000) Biodiversity hotspots for conservation priorities. Nature, 403, 853-858.

Naidoo, R., Balmford, A., Ferraro, P.J., Polasky, S., Ricketts, T.H. \& Rouget, M. (2006) Integrating economic costs into conservation planning. Trends in Ecology \& Evolution, 21, 681-687.

Naveda, A., De Thoisy, B., Richard-Hansen, C., Torres, D.A., Salas, L., Wallance, R. et al. (2008) Tapirus terrestris. In The IUCN Red List of Threatened Species. dx.doi.org/10.2305/IUCN.UK. 2008.RLTS.T21474A9285933.en [accessed 10 July 2018].

NorRIs, D. (2014) Model thresholds are more important than presence location type: understanding the distribution of lowland tapir (Tapirus terrestris) in a continuous Atlantic forest of southeast Brazil. Tropical Conservation Science, 7, 529-547.

Novaro, A.J., Redford, K.H. \& Bodmer, R.E. (2000) Effect of hunting in source-sink systems in the Neotropics. Conservation Biology, 14, 713-721.

Ojeda, R.A., Chillo, V. \& Diaz Isenrath, G.B. (2012) Red Book of the Threatened Mammals of Argentina. SAREM (Sociedad Argentina para el Estudio de los Mamíferos), Mendoza, Argentina.

Padilla, M. \& Dowler, R.C. (1994) Tapirus terrestris. Mammal Species, 481, 1-8.

PAInTER, R.L.E. (1998) Gardeners of the forest: plant-animal interactions in a Neotropical forest ungulate community. $\mathrm{PhD}$ thesis. University of Liverpool, Liverpool, UK.

Pearson, R.G., Dawson, T.P. \& Liu, C. (2004) Modeling species distribution in Britain: a hierarchical integration of climate and land-cover data. Ecography, 27, 285-289.

Perovic, P., de Bustos, S., Rivera, L., Arguedas Mora, S. \& Lizárraga, L. (2015) Strategic Plan for Conservation of Jaguars in the Southern Yungas of Argentina. National Park Administration, Secretary of Environment of Salta Province, Secretary of Environmental Management of Jujuy Province, and Latin-American School of Protected Areas, Salta, Argentina.

Petracca, L.S., Frair, J.L., Cohen, J.B., Calderón, A.P., Carazo-Salazar, J., Castañeda, F. et al. (2018) Robust inference on large-scale species habitat use with interview data: the status of jaguars outside protected areas in Central America. Journal of Applied Ecology, 55, 723-734.

Phillips, S.J., Anderson, R.P. \& Schapire, R.E. (2006) Maximum entropy modeling of species geographic distributions. Ecological Modelling, 190, 231-259.

Phillips, S.J. (2017) A Brief Tutorial on Maxent. Biodiversity Informatics Program, Center for Biodiversity and Conservation, American Museum of Natural History, New York, USA. 
biodiversityinformatics.amnh.org/open_source/maxent [accessed 2 February 2018].

Pidgeon, A.M., Rivera, L., Martinuzzi, S., Politi, N. \& Bateman, B. (2015) Will representation targets based on area protect critical resources for the conservation of the Tucuman parrot? The Condor, $117,503-517$.

Radeloff, V.C., Stewart, S.I., Hawbaker, T.J., Gimmi, U., Pidgeon, A.M., Flather, C.H. et al. (2010) Housing growth in and near United States protected areas limits their conservation value. Proceedings of the National Academy of Science, 107, 940-945.

Reboratti, C. (1998) The High Bermejo, Realities and Conflicts. La Colmena, Buenos Aires, Argentina.

Rivera, L., Politi, N., Lizárraga, L., Chalukian, S., de Bustos, S. \& Ruiz de los Llanos, E. (2015) Conservation Priority Areas for Threatened species From the Southern Yungas of Salta and Jujuy Provinces. CEBio, San Salvador de Jujuy, Argentina.

Roberts, C.M., Bohnsack, J.A., Gell, F., Hawkins, J.P. \& Goodridge, R. (2001) Effects of marine reserves on adjacent fisheries. Science, 294, 1920-1923.

Salta Government (2013) Integral Management and Development Plan of the Integrated Territorial Management Area Serranías de Tartagal. Salta Government Web, Salta, Argentina. y10oo394.ferozo. com/documentos/plan-de-manejo-acambuco [accessed 3 September 2018].

Schank, C., Mendoza, E., Vettorazzi, M.G., Cove, M.V., Jordan, C.A., O'Farrill, G. \& Leonardo, R. (2015) Integrating current range-wide occurrence data with species distribution models to map the potential distribution of Baird's tapir. The Newsletter of the IUCN/SSC Tapir Specialist Group, 24, 15-25.

Schank, C.J., Cove, M.V., Kelly, M.J., Mendoza, E., O’Farrill, G., REYNA-HuRTADo, R. et al. (2017) Using a novel model approach to assess the distribution and conservation status of the Endangered Baird's tapir. Diversity and Distributions, 23, 1459-1471.

Seghezzo, L., Volante, J., Paruelo, J., Somma, D., Buliubasich, E., Rodríguez, H. et al. (2011) Native forests and agriculture in Salta (Argentina). The Journal of Environment \& Development, 20, 251-277.

Setsaas, T.H., Holmern, T., Mwakalebe, G., Stokke, S. \& Røskaft, E. (2007) How does human exploitation affect impala populations in protected and partially protected areas? A case study from the Serengeti Ecosystem, Tanzania. Biological Conservation, $136,563-570$.

Simonetti, J.A. (1999) Diversity and conservation of terrestrial vertebrates in Chile. Revista Chilena de Historia Natural, 72, 493-50.

Soares-Filho, B.S., Nepstad, D.C., Curran, L.M., Cerqueira, G.C., Garcia, R.A., Ramos, C.A. et al. (2006) Modelling conservation in the Amazon basin. Nature, 440, 520-523.

Steenweg, R., Whittington, J., Hebblewhite, M., Forshner, A., Johnston, B., Petersen, D. et al. (2016) Camera-based occupancy monitoring at large scales: power to detect trends in grizzly bears across the Canadian Rockies. Biological Conservation, 201, 192-200.

Taber, A., Chalukian, S.C., Altrichter, M., Minkowski, K., LizÁrraga, L., Sanderson, E. et al. (2008) The Destination of the Neotropical Forest Architects: Evaluation of the Distribution and Conservation Status of White-Lipped Peccary and Lowland Tapir. IUCN/CSE Specialist Group on Wild pig, Peccary and Hippo, IUCN/CSE Specialist group on Tapir; Wildlife Conservation Society, and Wildlife Trust, New York, USA.

Tobler, M.W. (2008) The ecology of the lowland tapir in Madre de Dios, Peru: using new technologies to study large rainforest mammals. PhD thesis. Texas A\&M University, College Station, USA.

Trolle, M., Noss, A.J., Cordeiro, J.L.P. \& Oliveira, L.F.B. (2007) Brazilian tapir density in the Pantanal: a comparison of systematic camera trapping and line-transect surveys. Biotropica, 40, 211-217.

VanDerWal, J., Shoo, L.P., Graham, C. \& Williams, S.E. (2009) Selecting pseudo-absence data for presence-only distribution modeling: how far should you stray from what you know? Ecological Modelling, 220, 589-594.

Woodroffe, R. \& Ginsberg, J.R. (1998) Edge effects and the extinction of populations inside protected areas. Science, 280, 2126-2128.

Zeller, K.A., Nijhawan, S., Salom-Pérez, R., Potosme, S.H. \& Hines, J.E. (2011) Integrating occupancy modeling and interview data for corridor identification: a case study for jaguars in Nicaragua. Biological Conservation, 144, 892-901. 